fournal of Medical Genetics (1974). 11, 206-215.

\section{A sporadic case of apparent Crouzon's syndrome with extra- craniofacial manifestations}

Summary. A case is presented which may represent a fresh mutation with craniofacial characteristics of Crouzon's syndrome and skeletal abnormalities suggestive of Carpenter's syndrome together with mild skin syndactyly.

Dysostosis craniofacialis (Crouzon's syndrome) is a rare disorder infrequently mentioned in ophthalmic, genetic, and neurological literature. It is one of a group of closely related syndromes characterized by premature closure of coronal and sagittal sutures, hypertelorism, hypoplastic maxillae, relative mandibular prognathism, and ocular proptosis. Other less constant features include deafness, short upper lip, and partial anodontia. The condition is inherited as an autosomal dominant but many cases are sporadic due to new mutations. Variability occurs in the pattern of cranial and facial malformations. Premature closure of the coronal and sagittal sutures leads to the characteristic acrocephaly.

Crouzon (1912) did not describe any extracraniofacial manifestations of the disorder which now bears his name. Carpenter (1901) had previously described a similar entity of acrocephaly but showing extra-craniofacial manifestations. Temtamy (1966) has confirmed and amplified Carpenter's own observations and noted other anomalies including lateral displacement of the patellae and genu valgum. She also noted that some previously reported cases have been mistakenly identified as Apert's syndrome or Laurence-Moon-Biedl syndrome. Saethre (1931) described several cases resembling Crouzon's syndrome but with mild skin syndactyly of the index and long fingers and of the

Received 16 October 1973. third and fourth toes. Chotzen (1932/1933) also described a similar case but clearly distinguished these cases from those of Carpenter's syndrome. Vogt (1933) described four cases with the craniofacial appearances of Crouzon's syndrome but with moderately gross hand and foot malformations suggestive of Apert's syndrome. Nager and de Reynier (1948) coined the term Vogt's cephalo- \& syndactyly indicating the similarity to both conditions.

\section{Case Report}

The patient, a 19-year-old clerk, presented in September 1971 complaining of instability of the left knee, especially on climbing and running, present for nine years, but worse over the previous six months. The feeling of instability was accompanied by visible lateral subluxation of the left patella. She had no other complaints. Due to the onset of infantile hydrocephalus and premature suture closure, typical of Crouzon's syndrome, she was subjected to routine cranioplastic surgery at the ages of 1 and 5 years.

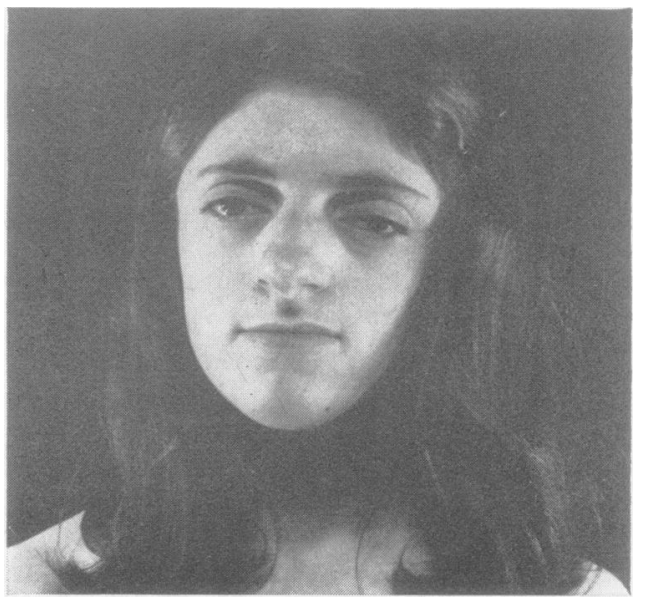

Fig. 1. Typical Crouzon facial deformities of hypertelorism, proptosis, maxillary hypoplasia, and relative mandibular prognathism. The characteristic 'beaking' of the nose is not very apparent in this view. 


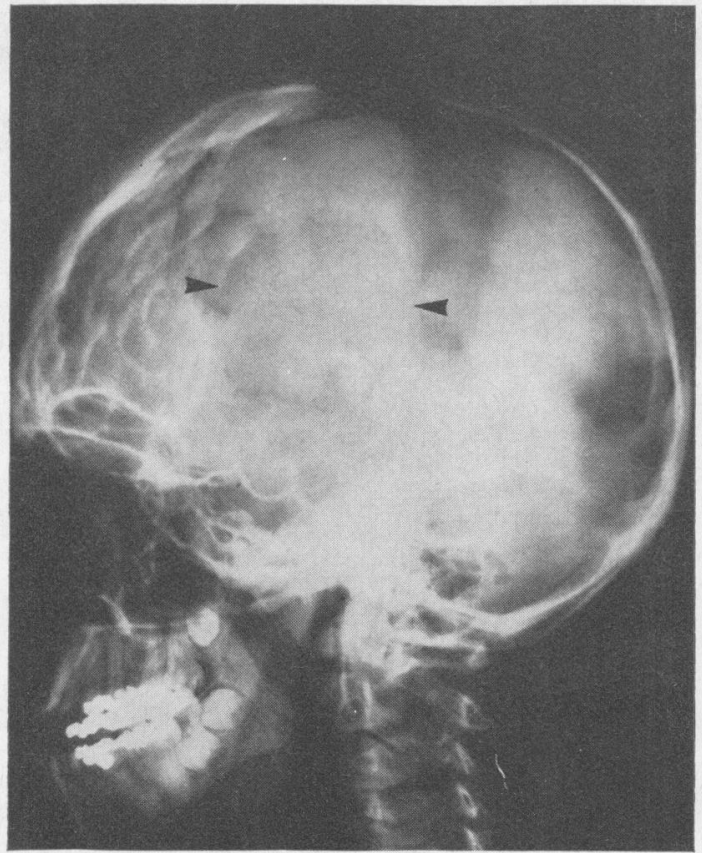

FIG. 2

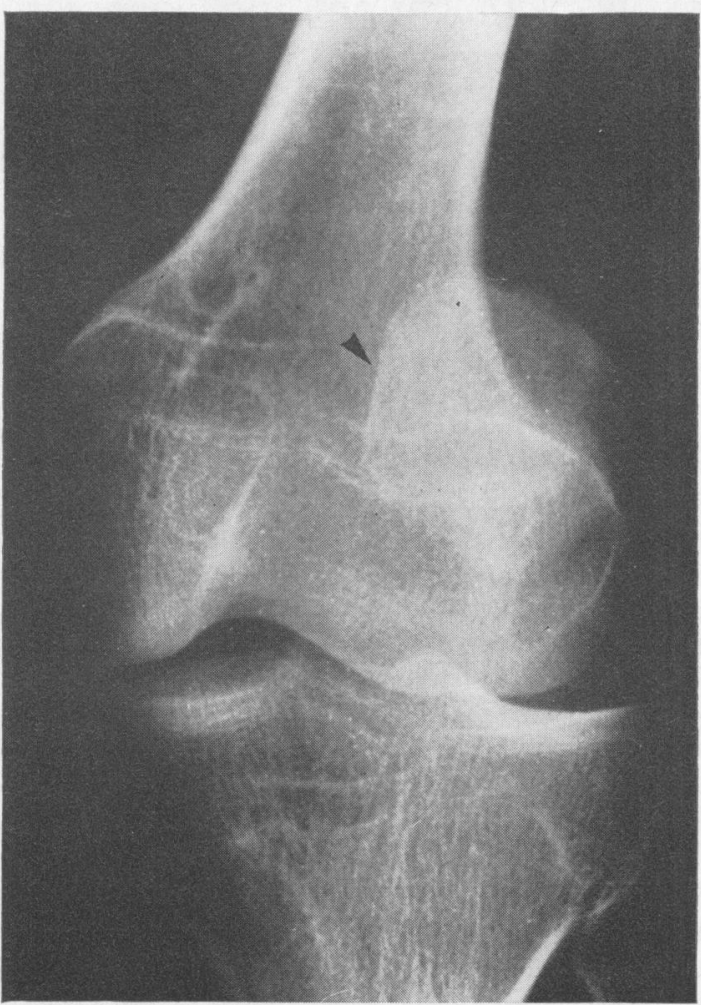

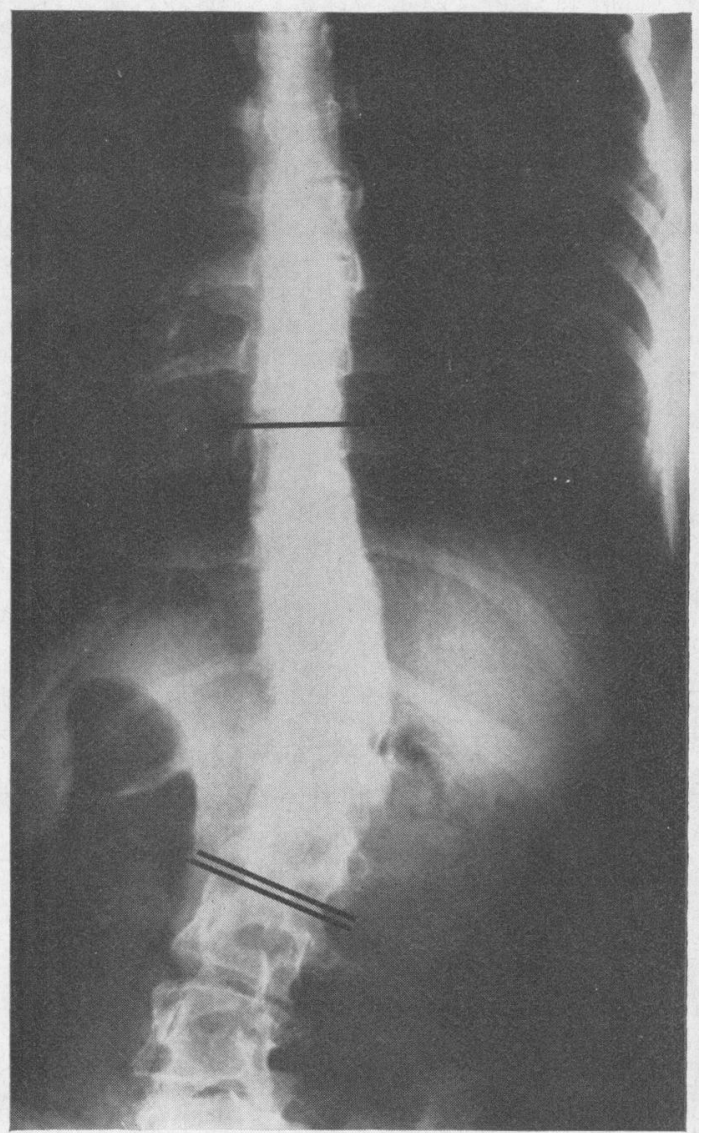

FIG. 4

Fig. 2. Lateral radiograph of the skull. This view of the skull shows evidence of the previous cranio-plastic surgery (arrowed). The 'copper beating' effect most marked in the frontal region is evidence of hydrocephalus produced by the craniostenosis. The presence of the maxillary hypoplasia and relative mandibular prognathism is confirmed.

FIG. 3. Antero-posterior radiograph of the left knee. This radiograph of the knee shows the lateral subluxation of the patella (arrowed) and the lateral femoral condyle hypoplasia. The valgus deformity at the left knee of $20^{\circ}$ is responsible for the apparent obliquity of the left knee on this view.

Fig. 4. Antero-posterior radiograph: thoraco-lumbar spine. This view of the spine shows a double primary scoliosis convex to the right in the thoraco-lumbar region and convex to the left in the lower lumbar region. This scoliosis is somewhat atypical since the curves do not match each other, as is normal in an idiopathic double scoliosis.

FIG. 3 
Clinical examination revealed a rather small young woman of $4 \mathrm{ft} 11$ in. in height. Her facies showed typical Crouzon deformities of beaked nose, hypertelorism, moderate ocular proptosis, and maxillary hypoplasia (Fig. 1). The skull showed residual acrocephaly modified by previous cranioplasties. Examination of the back revealed a double primary scoliosis with mild right thoracic and left lumbar rotation. There was a valgus deformity of $10^{\circ}$ at the left knee with a left patella subluxing in extension but reducing in flexion. Flexion of the left knee was restricted by $20^{\circ}$ compared to the right knee. The right knee appeared normal. Both feet manifested cutaneous syndactyly between the second and third toes. No other clinical abnormality was detected and routine biochemical and haematological investigations were normal. IQ at 15 years was normal.

Radiographs at this stage showed changes typical of Crouzon's syndrome in the skull and face (Fig. 2). The left knee showed a hypoplastic lateral femoral condyle and the presence of the scoliosis was confirmed (Figs. 3 and 4 ).

The patient was one of eight children. Examination of the parents and sibs did not reveal any abnormality, and enquiry into the family history did not show any further cases of Crouzon's syndrome. The parents were unrelated. At the birth of the patient the father's age was 45 , the mother's 38 .

Operation was carried out in September 1971 when the left patellar tendon was transposed medially and distally on the tibia. The patient made an uneventful recovery and when followed up one year after operation had no symptoms of instability in the left knee.

\section{Discussion}

This case shows the typical craniofacial manifestations of Crouzon's syndrome with mild skin syndactyly as described by Saethre (1931) and Chotzen (1932/1933) together with the femoral condyle hypoplasia and genu valgum as described by Temtamy (1966) in Carpenter's syndrome. The occurrence of scoliosis has so far not been documented as part of any of the syndromes mentioned above.

It is possible that this case represents a fresh mutation with craniofacial characteristics of Crouzon's syndrome and skeletal abnormalities suggestive of Carpenter's syndrome together with the mild skin syndactyly described by Saethre (1931) and Chotzen (1932/1933).

I wish to thank Miss Ruth Wynne-Davies for her help in preparing the paper and Professor J. I. P. James and $\mathrm{Mr}$ W. M. McQuillen for permission to study the case.

M. A. LeONARD

Department of Orthopaedics, Royal Victoria Infirmary, Newcastle upon Tyne

\section{REFERENCES}

Carpenter, G. (1901). Two sisters showing malformations of the skull and other congenital abnormalities. Report of the Society for the Study of Disease in Children, 1, 110-118.

Chotzen, F. (1932/1933). Eine eigenartige familiäre Entwicklungsstörung (Akrocephalosyndaktylie Dysostosis Craniofacialis und Hypertelorismus). Monatsschrift fïr Kinderheilkunde, 55, 97-122. Crouzon, O. (1912). Dysostose crano-faciale héréditaire. Bulletin Memoires de la Société Médicale des Hópitaux de Paris, 33, 545555.

Nager, F. R. and de Reynier, J. P. (1948). Das Gehörorgan bei den angeborenen Kopfmissbildungen. Practica Oto-rhino-laryngologica, 10 Suppl. 2, 1-128.

Saethre, H. (1931). Ein Beitrag zum Tarmschädelproblem (pathogenese Erblichkeit und Symtomatologie). Deutsche Zeitschrift für Nervenheilkunde, 119, 533-555.

Temtamy, S. A. (1966). Carpenter's syndrome. Acrocephalosyndactyly. An autosomal recessive syndrome. Fournal of Pediatrics, 69, 111-120.

Vogt, A. (1933). Dyskephalie (Dysostosis craniofacialis maladie de Crouzon 1912) und eine neuartige Kombination dieser Krankheit mit Syndaktylie der 4 Extermitäten (Dyskephalofaktylie). Klinische Monatsblätter für Augenheilkunde, 90, 441-454.

\section{Deletion of the long arms of the $\mathrm{Y}$ chromosome with normal male development and intelligence}

\section{Summary. Normal male develop-} ment was found in a man with a proven deletion of the long arms of the Y chromosome. The only phenotypic effect was on his build. This study offers additional proof that all, or most of the long arms of the $\mathrm{Y}$ chromosome are not primarily concerned with the determination of male sexual characteristics.

Large deletions of the $\mathrm{Y}$ chromosome resulting in small morphologically intact chromosomes with a 옹 centromere, give rise to a variety of phenotypic effects which have been described on at least six occasions. Telfer, Baker, and Rollin (1973) re- N ported it in a boy of short stature; Meisner and Inhorn (1972) in a severely retarded man and his normal brother; Nakagome et al (1965) in a severely $\mathrm{N}$ retarded boy; Muldal and Ockey (1962) described a family with muscular dystrophy and hypospadias; $c$ Vaharu et al (1961) reported a case of gonadal dysplasia in a 'female' with an enlarged phallus; and Lo ? and Kobernick (1965) found a deleted Y cell line in a

Received 12 November 1973. 